NEWSLETTER

\title{
SPECIAL ANNUAL MEETING EDITION
}

November 26, 1979

\section{Materials Research Society}

CONTENTS

- Summaries of Symposia at 1978 Annual Meeting

- Text of Acceptance Speech by W. 0. Baker for Von Hippel Award for 1978

- 1979 Annual Meeting

- Washington News--NSF Division of Materials Research
Welcome to the 1979 Annual Meeting of the Materials Research Society. The principal activity of this multidisciplinary society is its annual meeting, consisting of symposia organized around topics at the forefront of materials research. This year's meeting has been organized by John Poate (Be11 Labs), Kathy Taylor (General Motors), and Bill Geissen (Northeastern University).

\section{BAKER RECEIVES SOCIETY AWARD}

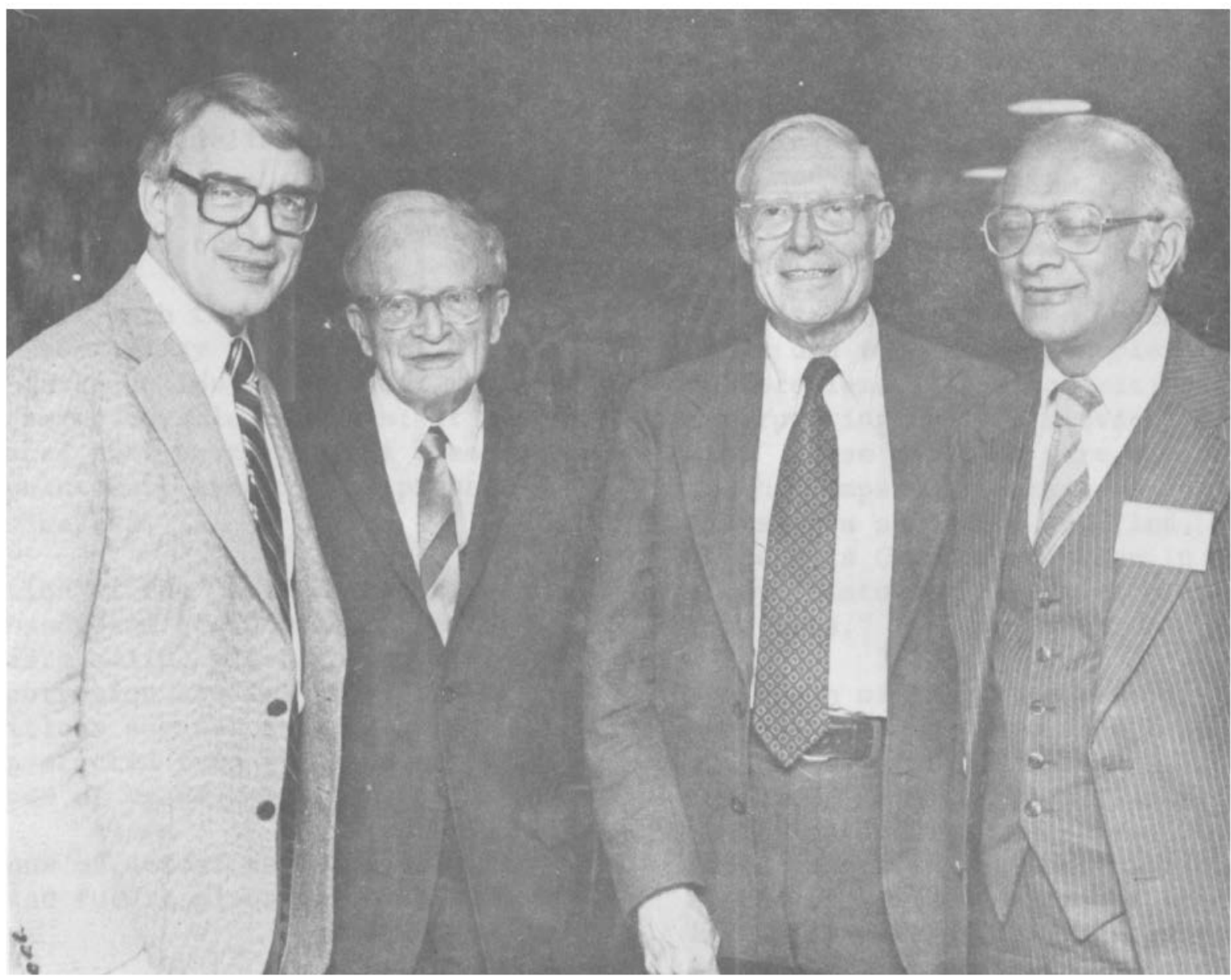

William 0. Baker, President of Bell Labs, receives the Von Hippel award recognizing outstanding service to materials research at the 1978 annual meeting of the Materials Research Society in Boston. Shown are (left to right) MRS President, Ken Jackson; Professor Von Hippe1; Dr. Baker; and past-MRS President, Rustum Roy. (Text of acceptance speech by $\mathrm{Dr}$. Baker on page 4.) 